\title{
Effect of nestbox type on occupancy and breeding biology of Tree Sparrows Passer montanus in central Spain
}

\author{
VICENTE GARCÍA-NAVAS, ${ }^{1 *}$ LUIS ARROYO, ${ }^{2}$ JUAN JOSÉ SANZ ${ }^{1}$ \& MARIO DÍAZ ${ }^{3}$ \\ ${ }^{1}$ Departamento de Ecología Evolutiva, Museo Nacional de Ciencias Naturales (CSIC), \\ José Gutiérrez Abascal, 2. E-28006 Madrid, Spain \\ ${ }^{2}$ Departamento de Ciencias Ambientales, Facultad de Medio Ambiente, \\ Universidad de Castilla-La Mancha. E-45071 Toledo, Spain \\ ${ }^{3}$ Instituto de Recursos Naturales, Centro de Ciencias Medioambientales (CSIC), \\ Serrano 115 bis. E-28006 Madrid, Spain
}

\begin{abstract}
Avian life-history studies are often conducted on populations nesting in nestboxes. However, the type of nestbox used is a potentially confounding variable, as each model shows specific characteristics. In recent decades, a new commercial model of artificial nestbox made of woodcrete, a mixture of sawdust and additives, has become popular owing to its better protection against predators compared with the classic wooden design. We assess the effect of nestbox type on the breeding ecology of Tree Sparrows Passer montanus, focusing on their thermal properties, an influential factor in nestbox selection. Occupancy rates and reproductive parameters of Tree Sparrows were compared between birds breeding in woodcrete and wooden nestboxes over 5 years. Woodcrete nestboxes had a higher occupancy rate and birds breeding in them had earlier clutches, a shorter incubation period and more reproductive attempts per season than birds nesting in wooden boxes. Clutch size and nestling condition did not differ between nestbox types, but reproductive success was higher in woodcrete nestboxes. The higher temperature in woodcrete nestboxes $\left(1.5^{\circ} \mathrm{C}\right.$ higher on average) might explain these differences. Such differences may bias results obtained in comparative studies where more than one nestbox type is used.
\end{abstract}

Keywords: breeding ecology, laying date, nestbox, Passer montanus, temperature, Tree Sparrow.

Many long-term avian life-history studies have been conducted on hole-nesting species breeding in artificial nestboxes (Møller 1989). In the last 10 years or so, several studies have compared the breeding biology of birds nesting in natural and artificial sites (Major \& Kendal 1996, Purcell et al. 1997, Wilson et al. 1998, King et al. 1999, Berry \& Lill 2003, Mezquida \& Marone 2003, Mitrus 2003, Burke et al. 2004, Robinson et al. 2005). Møller (1989) suggested that the results of some nestbox studies are potentially biased due to factors such as nest predation. Recently, a new type of commercial nestbox has become available to replace the traditional wooden

${ }^{*}$ Corresponding author.

Email: vicenteg_navas@yahoo.es design. Woodcrete nestboxes, made with a mixture of cement and sawdust, greatly reduce nest predation (McCleery et al. 1996) and last longer. These nestboxes also differ in other characteristics, such as their internal volume. Woodcrete and wooden nestboxes are made with materials with different thermal properties, and this might have effects on the breeding biology of birds. It is necessary to test the effects of nestbox type on the breeding biology of birds to determine whether studies done with different nestboxes are comparable and to ascertain which model is more suitable for each species.

Temperature is one of the main cues that determine gonadal development and therefore the timing of egg-laying in passerine birds (Kluijver 1952). The thermal environment affects the energy expenditure 
of birds, which can have consequences for their reproductive performance (Pendlebury et al. 2004). Low temperatures raise metabolic demands for body maintenance, and so reduce the energy available for egg production (Nager \& van Noordwijk 1992, Yom-Tov \& Wright 1993). This may influence the timing of egg-laying and possibly indirectly the final clutch size (Yom-Tov \& Hilborn 1981). By contrast, high temperatures in the nest might cause thermal stress of chicks, and this may reduce fledging success (King \& Farner 1961, van Balen \& Cavé 1970, Thomas et al. 2001).

The effect of nest microclimate on various breeding parameters has been investigated in studies in which warmer nestboxes were compared with cooler ones. O'Connor (1978) and Dhondt and Eyckerman (1979) found earlier laying of tits (Parus and Cyanistes spp.) breeding in nestboxes with warmer microenvironments (better insulation or exposure to the afternoon sun, respectively), in accordance with the 'energy limitation' hypothesis. According to this hypothesis, the timing of breeding might be constrained early in the season by a limited supply of energy needed by the female for egg production (Perrins 1970). By heating and cooling nestboxes of Great Tits Parus major, Nager and van Noordwijk (1992) showed that birds changed their nest-building behaviour and invested less energy in egg formation (reflected in a reduction in egg volume) when increasing their energetic requirements for maintenance, but this experimental protocol did not affect their laying date. In a study with captive Starlings Sturnus vulgaris having food available ad libitum, changes in ambient temperature had direct effects on the timing of egg-laying independently of food availability or photoperiod (Meijer et al. 1999). In an experiment manipulating pre-laying nestbox temperature in Blue Tits Cyanistes caeruleus, layinggaps were less frequent in heated than in control nestboxes (Yom-Tov \& Wright 1993).

The two nestbox types used in the present study are made of materials which differ in their capacity to transmit radiant energy. Woodcrete heats up faster and presents a greater 'waste heat effect' (stores more heat) than wood, a much more insulating material. The aim was to assess the effects of the type of nestbox (woodcrete vs. wooden) on the occupancy rate and breeding biology of Tree Sparrows Passer montanus in southern Europe. Potential differences in occupancy rates, timing of breeding, clutch size, incubation period and breeding success may result from differences in the insulation properties of the nestbox models. We assessed whether higher temperatures inside the woodcrete nestboxes led to earlier and larger clutches, shorter incubation periods and a favourable effect on nestling growth rate, size and survival.

\section{METHODS}

In Spain, the Tree Sparrow is a bird of rural areas, open farmland and small isolated woods. It also inhabits large gardens, especially where nestboxes are provided. Both sexes co-operate when building their nests, carrying diverse materials including plant stems, rootlets, leaves, grasses, pine needles, feathers, down and artificial material (e.g. paper, threads). The nest is a spherical structure, with a side entrance leading to the nest cup; in holes, available space is normally filled with material, although the roof can be omitted (see Cramp \& Perrins 1993, SummersSmith 1995). In Spain, this species lays one to three clutches per season from April to mid-August (Sánchez-Aguado 1984).

\section{Study area}

The study was conducted in Toledo, central Spain $\left(39^{\circ} 51^{\prime} \mathrm{N}, 4^{\circ} 01^{\prime} \mathrm{W}\right)$ from 2002 to 2006 . The study area comprised 15 ha of gardens, suburban habitats and riverside forest close to the Tagus River inside the Castilla-La Mancha University campus (for more details see Arroyo et al. in press). The climate is Mediterranean continental with very little precipitation and a mean annual temperature of $15^{\circ} \mathrm{C}$. Average minimum (January) and maximum (July) monthly temperatures are 6.5 and $25.9{ }^{\circ} \mathrm{C}$ respectively, and large daily thermal oscillations are common (Aranda 1982).

\section{Experimental design}

At the end of 2001, 50 pairs of nestboxes were erected in our study area. Each pair was composed of a wooden and woodcrete nestbox (type 1B, Schwegler, Schorndorf, Germany) placed in the same tree or in adjacent trees $(<5 \mathrm{~m}$ apart), and hung from branches at heights of 3-4 m with the same orientation. The wooden and woodcrete nestboxes had internal volumes of 2057 and $1869 \mathrm{~cm}^{3}$, respectively. The wooden nestboxes had a quadrangular shape and the distance between entrance hole and the base was smaller than in the woodcrete nestboxes. Woodcrete nestboxes were cylindrical, narrower and 
deeper, creating a more closed cavity. Both models had an entrance hole $32 \mathrm{~cm}$ in diameter and were cleaned every February. Old nest material was not removed after the breeding season so as not to harm birds that used the cavity as a roosting place over the autumn and winter. There were few nest predation attempts owing to the absence of mammalian and avian predators throughout the study years. Horseshoe Snakes Hemorrhois hippocrepis predated a very small number of nests. Therefore, predation risk did not significantly affect the occupancy of our nestboxes.

In spring 2005, 12 electronic temperature dataloggers (ESCORT Junior, ESCORT Data Logging Systems Ltd, Auckland, New Zealand) were placed in the tops of six closely spaced wooden and woodcrete nestboxes occupied by Tree Sparrows during the nest-building period. The presence of the datalogger did not modify the behaviour of the breeding birds and only one out of the 12 pairs abandoned during the incubation period (8.3\%), a desertion rate similar to that of birds in nestboxes without dataloggers $(9.5 \%, n=43)$. Daily temperature (mean, maximum, minimum) inside the nestboxes was recorded once every hour over 75 days ( 8 March to 21 May), the approximate duration of the majority of first broods. Daily ambient temperature (mean, maximum and minimum) was obtained from the meteorological station located in the study area (Castilla-La Mancha University campus, Toledo).

Only data from true first clutches were considered except in 2006, when second and third clutches also were monitored. In previous years, fieldwork was conducted from March to June. Frequent checks of the nestboxes provided data on clutch initiation date, clutch size and hatching date for all breeding pairs. The incubation period was defined as the number of days between completion of the clutch and the first signs of hatching. Nestlings were measured and ringed (ICONA, Spanish Ministry of Environment) when they were 10 days old. Nestlings were weighed to the nearest $0.1 \mathrm{~g}$ with an electronic balance, their tarsus length was measured to the nearest $0.01 \mathrm{~mm}$ with a digital calliper and wing length was measured to the nearest $1 \mathrm{~mm}$ with a top ruler using the 'max' method of Svensson (1992). Broods were visited daily from day 18 onwards to establish the number of fledged young. Two partial measures of reproductive success were considered: hatching success as the proportion of eggs hatched, and breeding success as the proportion of eggs that resulted in fledglings.

\section{Statistical analyses}

All statistical analyses were performed with STATISTICA 6.0 (StatSoft Inc., Tulsa, OK, USA) and were two-tailed. Differences in temperature (mean, maximum and minimum) between nestbox types were assessed using paired Student's $t$-tests. A Pearson correlation was used to assess the relationship between ambient and internal nestbox temperatures. Occupancy rates were analysed by fitting log-linear models to the three-way contingency tables generated by the factors year, nestbox type and nestbox state (occupied or empty). The use frequency of woodcrete and wooden nestboxes throughout the five study years was compared using Wilcoxon tests comparing the average of each matched nestbox type. The same analyses were used for testing differences between nestbox types in mean number of clutches and mean number of fledglings over a complete breeding season (March-August).

Breeding parameters were checked for statistical normality using the Kolmogorov-Smirnov test. The influence of nestbox type on breeding parameters was analysed using General Linear Models. All nonsignificant terms between factors and covariates were removed from the final Ancova models. $A$ posteriori contrasts were assessed with least significant difference (LSD) tests. The frequency of nest failures was analysed by fitting log-linear models to the threeway contingency tables generated by the factors year, nestbox type and nest success (deserted brood or non-deserted brood). In these two last analyses, the first study year was excluded due to small sample size (2002; woodcrete $n=12$, wooden $n=3$ ). To allow the use of parametric tests, hatching and breeding successes were arcsine square roottransformed. All values are presented as means $\pm \mathrm{sd}$, unless stated otherwise.

\section{RESULTS}

\section{Temperature inside nestbox types}

Mean and maximum daily temperatures differed significantly between nestbox types, being on average 1.52 and $2.94{ }^{\circ} \mathrm{C}$ higher in the woodcrete nestboxes than in the wooden boxes, respectively (Table 1). Minimum temperatures did not differ significantly between nestbox types. Over the range of temperatures observed, woodcrete nestboxes were always warmer than wooden nestboxes, and the difference 
Table 1. Mean, maximum and minimum temperatures $\left({ }^{\circ} \mathrm{C}\right)$ in relation to nestbox type, 8 March-21 May 2005. This period comprises egg-laying, incubation and brood periods for the first breeding attempt.

\begin{tabular}{|c|c|c|c|c|}
\hline & \multicolumn{2}{|c|}{ Nestbox } & \multirow[b]{2}{*}{ Paired $t$-test } & \multirow[b]{2}{*}{$P$} \\
\hline & Woodcrete & Wooden & & \\
\hline Mean & $18.02 \pm 0.73$ & $16.50 \pm 0.26$ & 4.22 & 0.008 \\
\hline Maximum & $28.32 \pm 1.51$ & $25.38 \pm 1.01$ & 10.42 & $<0.001$ \\
\hline Minimum & $10.09 \pm 1.38$ & $9.22 \pm 0.57$ & 1.37 & 0.23 \\
\hline
\end{tabular}

Values are means $\pm s d$. Sample size was six for each nestbox type.

increased with increasing ambient temperature during both diurnal and nocturnal periods (Fig. 1).

\section{Occupancy rate}

Tree Sparrows showed a clear preference for woodcrete nestboxes. Occupancy rate of wooden nestboxes was on average $33.5 \%$ whereas that of woodcrete boxes was $76.5 \%$ (log-linear modelling: $G_{1}^{2}=72.80$, $P<0.001)$. This pattern held through the whole study period (nestbox type $\times$ year: $G_{4}^{2}=2.63$, $P=0.62$ ), although there was a significant difference in occupancy rates among years (year: $G_{4}^{2}=57.07$, $P<0.001$ ), due to low occupancy in the first study year (2002: 15\%; 2003: 50\%; 2004: 58\%; 2005: 53\%; 2006: 59\%). Considering only first broods, the mean number of years that a nestbox was used differed significantly between nestbox types (Wilcoxon matched pair test, $Z=5.77, n=50$ dyads of nestboxes, $P<0.001)$. Over the 5 years of study, woodcrete and wooden boxes were occupied on average in 3.66 and 1.52 years, respectively. The mean number of breeding attempts also differed between nestbox types (Wilcoxon test, $Z=3.90$, $n=48$ dyads of nestboxes, $P<0.001$ ) when considering a complete breeding season (2006). The mean number of clutches was $2.02 \pm 1.16(n=49)$ and $0.97 \pm 1.05(n=49)$ for woodcrete and wooden nestboxes, respectively.

\section{Laying date, clutch size and incubation period}

Mean laying date of first clutches was $14.14 \pm 10.07$ (days from 1 April, $n=220$ ). Mean laying date was earlier in woodcrete than in wooden nestboxes (ANOVA, nestbox type: $F_{1,212}=13.55, P<0.001$ ), although this difference was only significant in two

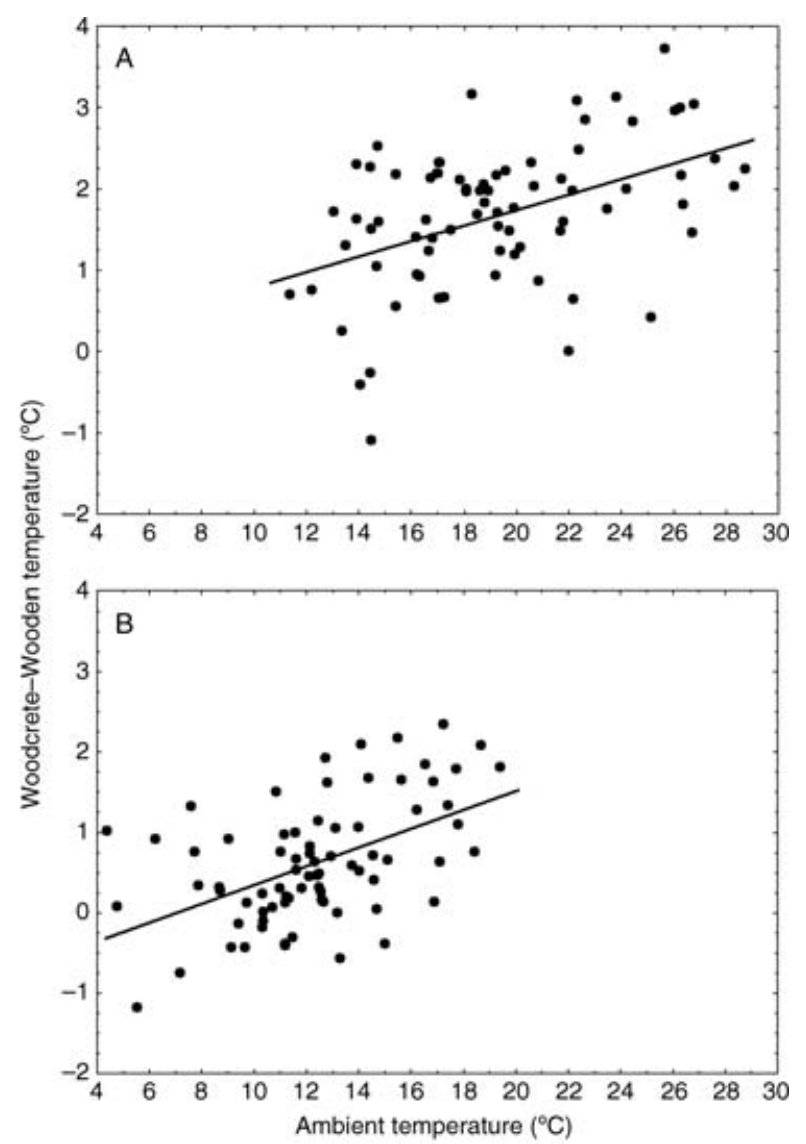

Figure 1. Linear regression of the daily difference in temperature between woodcrete and wooden nestboxes on the mean ambient temperature of $(\mathrm{A})$ daylight (difference $=$ $-0.146+0.0944 \times$ ambient temperature, $r=0.41, F_{1,73}=3.94$, $P<0.001$ ) and (B) nocturnal hours (difference $=-0.829+$ $0.117 \times$ ambient temperature, $\left.r=0.48, F_{1.73}=4.69, P<0.001\right)$. Daytime and night time were estimated from the date-specific times of sunset and sunrise.

out of the four study years $(2003,2006$; Fig. 2; LSD a-posteriori test; year $\times$ nestbox type interaction: $\left.F_{3,212}=5.63, P=0.001\right)$. Mean laying date also differed significantly between years (year: $F_{3,212}=8.40$, $P<0.001$ ).

Mean clutch size was $4.80 \pm 0.67(n=220)$. For Tree Sparrows breeding in woodcrete and in wooden nestboxes, clutch size ranged from three to seven eggs and from two to six eggs, respectively. Clutch size was significantly related to laying date $(\beta=0.009$, $t=1.85, P=0.05$ ) but was not affected by nestbox type (ANCOVA, $F_{1,211}=2.59, P=0.108$ ) or study year (ANCOVA, $F_{3,211}=0.64, P=0.58$ ). The effect of nestbox type on clutch size did not differ among years (ANCOVA, year $\times$ nestbox type: $F_{3,211}=2.20$, $P=0.08)$. 


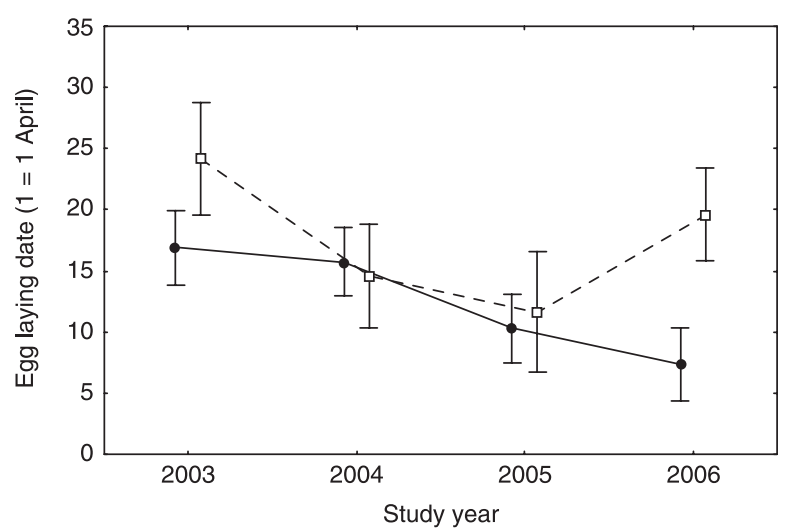

Figure 2. Mean ( \pm se) laying date of Tree Sparrows breeding in woodcrete and wooden nestboxes in the different study years (filled circles $=$ woodcrete nestboxes, open squares $=$ wooden nestboxes).

Mean incubation period was $10.84 \pm 1.14$ days (range $8-14, n=211$ ). Incubation period decreased significantly with laying date $(\beta=-0.17, t=2.63$, $P<0.01)$ and was not significantly related to clutch size $(\beta=0.07, t=0.65, P=0.51)$. Incubation period differed significantly among years and nestbox types after controlling for the significant effect of laying date on incubation period (ANCOVA, year: $F_{3,205}=$ 12.74, $P<0.001$; nestbox type: $F_{1,205}=12.74, P<$ 0.001 , year $\times$ nestbox type: $F_{3,201}=0.34, P=0.79$ ). Incubation periods were shorter for pairs breeding in woodcrete than in wooden nestboxes (wooden: $11.1 \pm 1.2$ days, woodcrete: $10.8 \pm 1.2$ days).

\section{Nestling condition}

Mean size of nestlings did not differ between nestbox types (tarsus length: $16.43 \pm 0.83 \mathrm{~mm}$, wing length: $39.07 \pm 4.61 \mathrm{~mm}, n=173$; Table 2). These results did not change when study year, laying date and brood size were included in the model. Mean nestling body mass was $15.33 \pm 2.61 \mathrm{~g}(n=173)$, and also did not differ between nestbox types after accounting for the significant effects of laying date and tarsus length on body mass.

\section{Breeding success}

There were no differences between nestbox types on hatching success $(0.81 \pm 0.29, n=220$; Table 2$)$, but birds nesting in woodcrete nestboxes had a higher absolute reproductive success as compared with pairs in wooden nestboxes $(0.81 \pm 0.27$ and
Table 2. Results of Generalized Linear Model analyses (ANOVA or ANCOVA) testing the effects of different explanatory terms (year, nestbox type, laying date, clutch size or brood size) on five response variables (nestling tarsus length, wing length and body mass, hatching and breeding success).

\begin{tabular}{|c|c|c|c|}
\hline & $d f$ & $F$ & $P$ \\
\hline \multicolumn{4}{|c|}{ Nestling tarsus length (mm) } \\
\hline Year $^{*}$ & 3,169 & 8.93 & $<0.001$ \\
\hline Nestbox type & 1,163 & 0.76 & 0.38 \\
\hline Year $\times$ nestbox type & 3,163 & 0.79 & 0.50 \\
\hline Laying date & 1,163 & 3.25 & 0.07 \\
\hline Brood size & 1,163 & 2.38 & 0.12 \\
\hline \multicolumn{4}{|c|}{ Nestling wing length (mm) } \\
\hline Year $^{*}$ & 3,169 & 12.64 & $<0.001$ \\
\hline Nestbox type & 1,163 & 2.37 & 0.12 \\
\hline Year $\times$ nestbox type & 3,163 & 0.73 & 0.53 \\
\hline Laying date & 1,163 & 2.95 & 0.08 \\
\hline Brood size & 1,163 & 0.09 & 0.75 \\
\hline \multicolumn{4}{|l|}{ Nestling body mass (g) } \\
\hline Year $^{*}$ & 3,167 & 8.12 & $<0.001$ \\
\hline Nestbox type & 1,162 & 0.27 & 0.60 \\
\hline Year $\times$ nestbox type & 3,162 & 0.50 & 0.67 \\
\hline Laying date* & 1,167 & 4.74 & 0.030 \\
\hline Brood size & 1,162 & 0.06 & 0.98 \\
\hline Nestling tarsus length* & 1,167 & 112.65 & $<0.001$ \\
\hline \multicolumn{4}{|l|}{ Hatching success (\%) } \\
\hline Year* & 3,215 & 3.56 & 0.014 \\
\hline Nestbox type & 1,210 & 0.37 & 0.53 \\
\hline Year $\times$ nestbox type & 3,210 & 1.18 & 0.31 \\
\hline Laying date & 1,210 & 0.013 & 0.90 \\
\hline Clutch size ${ }^{*}$ & 1,215 & 4.55 & 0.034 \\
\hline \multicolumn{4}{|l|}{ Breeding success (\%) } \\
\hline Year* & 3,215 & 5.61 & $<0.001$ \\
\hline Nestbox type* & 1,215 & 4.02 & 0.046 \\
\hline Year $\times$ nestbox type & 3,210 & 2.01 & 0.11 \\
\hline Laying date & 1,210 & 0.91 & 0.34 \\
\hline Clutch size & 1,210 & $<0.01$ & 0.96 \\
\hline
\end{tabular}

Asterisks indicate the statistics for the final models including only significant terms.

$0.79 \pm 0.82$ in woodcrete and wooden nestboxes; $n=152$ and $n=68$, respectively; Table 2 ). When all clutches laid in the same breeding season were considered (data for 2006 only), total number of fledglings differed significantly between nestbox types, being larger in woodcrete nestboxes (Wilcoxon matched pair test, $Z=4.18, n=48$ dyads of nestboxes, $P<0.001)$. Mean number of fledglings was $6.14 \pm 4.31(n=49)$ in woodcrete and $2.63 \pm 3.25$ $(n=49)$ in wooden nestboxes.

The number of failed nests differed among study years (log-linear modelling; year: $G_{3}^{2}=12.82$, $P=0.005$ ) and between nestbox types (nestbox type: $G_{1}^{2}=4.40, P=0.035$ ). Woodcrete nestboxes contained a lower proportion of failed nests than 
wooden nestboxes and this difference did not vary among years (woodcrete: $17.6 \%$, wooden: $28.1 \%$; year $\times$ nestbox type: $G_{1}^{2}=4.32, P=0.228$ ).

\section{DIscussion}

Tree Sparrows showed a clear preference for breeding in woodcrete nestboxes rather than in wooden ones. The paired experiment suggested that environmental factors, such as box location or direction of entrance, could be disregarded as influencing occupancy rates. These results are in agreement with those reported from the UK by Browne (2006), who found that Great Tits and Blue Tits prefer to breed in woodcrete nestboxes rather than in wooden ones. Here we demonstrate that the two nestbox types also differ in thermal microclimate during the breeding season. Woodcrete nestboxes were warmer than wooden ones probably because woodcrete has a greater thermal conductivity than wood and, consequently, better transmitted ambient heat during the daytime. By contrast, the high thermal inertia of wood meant that, during the night, temperature differences between nestbox types were less marked. Temperature differences between nestbox types might be less obvious in northern latitudes than in the Mediterranean region, as existing differences in thermal microenvironment between both models are attributable to radiant energy. Microclimate inside each nestbox type may play a key role in nest-site selection and in the later development of reproductive performance.

Kluijver (1952) suggested that birds laid earlier in warm springs than cool ones because females preparing to breed under warm conditions would need fewer resources to maintain themselves and could therefore get into breeding condition more quickly (a long-term effect). This has been supported by several studies (Lack 1966, van Balen 1973, Slagsvold 1976), demonstrating a significant correlation between spring temperature and the onset of egg-laying. Many small passerines start egg formation after an increase in ambient temperature (a short-term effect, Perrins \& McCleery 1989). This short-term effect acts to fine-tune the initiation of egg-laying to the onset of a warming trend. In agreement with this hypothesis, Tree Sparrows breeding in woodcrete nestboxes showed an earlier laying date than those breeding in wooden nestboxes. This difference was found in two $(2003,2006)$ of four study years. Springs with high thermal variability (like those of 2004 and 2005 in our study area) might attenuate differences in thermal microenvironment between both nestbox types. Nevertheless, this does not seem to be wholly responsible for the observed interannual variation. Changes in population hierarchy (e.g. an increase in the proportion of inexperienced breeders) might also be involved.

Thermal insulation properties of woodcrete nestboxes may reduce female thermoregulatory costs and provide indirect evidence for energetic constraints during the egg-laying period (Perrins 1970, 1996, Stevenson \& Bryant 2000). This property could also be important during the incubation period. According to the 'energetic-bottleneck' hypothesis, incubation represents a phase with a high energetic demand (Yom-Tov \& Hilborn 1981). The shorter incubation periods in woodcrete nestboxes than in wooden nestboxes could be attributed to the fact that the energy saved by females breeding in woodcrete nestboxes allows them to increase nest attendance (Bryan \& Bryant 1999). Another possible explanation is that eggs in woodcrete nestboxes do not cool as rapidly as those in wooden nestboxes when females are foraging outside the nest. Thus, females nesting in woodcrete nestboxes would need less energy to compensate for the heat loss of eggs (Haftorn 1988) and this could affect the length of the incubation period. By contrast, clutch size was not affected by nestbox type. This last parameter has been related to other nestbox attributes in some studies with hole-nesting birds (see below).

The higher temperatures recorded in woodcrete nestboxes did not affect nestling condition or growth rate. Prolonged exposure to high temperatures can severely impact the health status of nestlings via dehydration and heat stress. In a study on the energy balance of the House Sparrow Passer domesticus, Kendeigh (1969) estimated the upper critical ambient temperature beyond which activity leads to hyperthermia at $37^{\circ} \mathrm{C}$. Records of nestbox temperatures show that nestlings rarely experience temperatures in excess of $35^{\circ} \mathrm{C}$. In this respect, studies on Blue Tit populations nesting in woodcrete nestboxes from France to Morocco did not show any reduction in reproductive success across the range known for this species (Isenmann et al. 1982, Moali et al. 1992). In fact, Tree Sparrows in woodcrete nestboxes produced a higher proportion of eggs that resulted in fledglings compared with wooden nestboxes. The proportion of nest failures was also lower in woodcrete nestboxes, whilst hatching success did not differ between nestbox types. Taking into account the complete breeding period, from March until early August, 
there was no effect of nestbox type on nestling physical condition (V. García-Navas et al. unpubl. data). Therefore, our results suggest that woodcrete nestboxes might have a beneficial effect on some breeding parameters and, although we did not measure physiological responses, temperatures recorded inside the woodcrete nestboxes are probably not sufficiently high to result in nestling hyperthermia in southern Europe. The fact that birds maintain their preference throughout the complete breeding season year after year suggests that birds could perceive woodcrete nestboxes as offering better nesting conditions.

It is also possible that the main driver of selection of woodcrete nestboxes is linked to their thermal insulation properties during the winter, as nestboxes are used for roosting by Tree Sparrows in the study area. This may have a direct impact on the number of nesting birds in each type of nestbox during the following breeding season (e.g. Pulido \& Díaz 2000). Moreover, non-thermal factors related to the nestbox design, such as outward appearance, internal darkness or internal volume, could also have effects on nestbox selection. Wooden nestboxes have a greater internal volume and quadrangular shape, requiring a larger amount of nest material and a more complex structure of the nest (V. García-Navas pers. obs.). Nestbox area may also affect clutch size (Karlsson \& Nilsson 1977, van Balen 1984, Gustaffson \& Nilsson 1985), although, in our study, there were no differences between woodcrete and wooden nestboxes in clutch size. This could be attributable to woodcrete nestboxes being smaller (this might entail smaller clutches) but having a more favourable microclimate (this might entail larger clutches) than those of wood; these two effects are opposing and for this reason it is possible that we have not detected an effect of nestbox model on clutch size.

Wooden nestboxes were less frequently used than woodcrete nestboxes and were rarely occupied in two consecutive breeding seasons. The number of years that woodcrete nestboxes were occupied was twice as high as for wooden nestboxes. This result suggests that wooden nestboxes may be used as temporary breeding sites until an empty woodcrete nestbox becomes available. Once a pair manages to occupy a woodcrete nestbox, it appears to have a greater fidelity, returning to breed over several consecutive breeding attempts. As there is a preference for nesting in woodcrete boxes, interspecific competition might operate in the pattern of nestbox occupancy. Birds breeding in woodcrete nestboxes may be on average older, more experienced and/or in better condition. Competitively inferior pairs may be relegated to wooden nestboxes and this fact might influence the differences found on some breeding parameters between nestbox types. To discern the relative importance of parental and nestbox quality on breeding performance, an experimental study changing the nestbox type (wooden to woodcrete and vice versa) at the end of the laying period could be performed.

In recent years, nestbox schemes have been increasingly used to provide Tree Sparrows with suitable nesting sites. This formerly common species has undergone a dramatic decline in population abundance and range in Europe, probably due to agricultural intensification and specialization of farming systems. In the UK, the Tree Sparrow is now red-listed as a species of high conservation concern, having declined by $75 \%$ in the period 1972-1996 (Donald et al. 2001, BirdLife International 2004, Field \& Anderson 2004). Here, we show that the woodcrete nestbox is the most suitable model for this species because of its high acceptance and the observed effects in the development of the later reproductive performance.

The importance of nestbox type has often been ignored. The types of nestboxes used may vary within studies, and the types used are often not even mentioned in the methodology. Long-term studies should consider potential effects of nestbox type on breeding ecology, particularly when a change in nestbox type has taken place in the course of the study. Furthermore, studies that gather data from different nestbox populations should take into account the nestbox type at plot level, especially if the main goal is to study temporal or spatial changes in reproductive parameters. Finally, the provision of woodcrete nestboxes may negatively affect the mismatch between the timing of the bird's breeding and its food supply, in those species for which synchronization between offspring requirements and food availability is a crucial determinant of reproductive success (e.g. Visser et al. 1998).

This study began as two BA dissertations in Environmental Sciences (L.A. and V.G.N.). We would like to thank Jesús Sánchez, Alfonso Menchén, Marian Palomares, Silvia Martínez, Belén Montero, Elvira Uzábal, Eva MuñozQuirós, Vanesa Sánchez, Diana Torres, Iván Vázquez and Verónica Salcedo for help during the 5 years of fieldwork. Manuel de Castro provided temperature data from the Meteorology Station at the Environmental Sciences Faculty. We are very grateful to Ruedi G. Nager, Paul F. Donald and 
two anonymous referees for numerous valuable comments and criticisms on the manuscript. Paul F. Donald, Ruedi G. Nager and Christian Smit also reviewed the English and improved earlier drafts.

\section{REFERENCES}

Aranda, F. 1982. Observaciones sobre el clima de Toledo. Toledo: Instituto Provincial de Investigaciones y Estudios Toledanos (IPIET).

Arroyo, L., García-Navas, V., Díaz, M. \& Sanz, J.J. in press. Uso de cajas-nido por la comunidad de aves trogloditas del Campus Universitario de la Fábrica de Armas de Toledo. Anuario Ornitológico de Toledo 2.

van Balen, J.H. 1973. A comparative study of the breeding ecology of the Great Tit Parus major in different habitats. Ardea 61: 193.

van Balen, J.H. 1984. The relationship between nest-box size, occupation and breeding parameters of the Great Tit Parus major and some other hole-nesting species. Ardea 72: 163175.

van Balen, J.H. \& Cavé, A.J. 1970. Survival and weight loss of nestling Great Tits Parus major, in relation to brood-size and air temperature. Neth. J. Zool. 20: 464-474.

Berry, L. \& Lill, A. 2003. Do predation rates on artificial nests accurately predict predation rates on natural nests? The effects of nest type, egg type and nest-site characteristics. Emu 103: 207-214.

BirdLife International. 2004. Birds in Europe: Population Estimates, Trends and Conservation Status. BirdLife Conservation Series No. 12. Cambridge, UK: BirdLife International.

Browne, S.J. 2006. Effect of nest box construction and colour on the occupancy and the breeding success of nesting tits Parus spp. Bird Study 53: 187-192.

Bryan, S.M. \& Bryant, D.M. 1999. Heating nest-boxes reveals an energetic constraint on incubation behaviour in great tits, Parus major. Proc. R. Soc. Lond. B 266: 157-162.

Burke, D.M., Elliott, K., Moore, L., Dunford, W., Nol, E., Phillips, J., Holmes, S. \& Freemark, K. 2004. Patterns of nest predation on artificial and natural nests in forests. Conserv. Biol. 18: 381-388.

Cramp, S. \& Perrins, C.M. (eds) 1993. The Birds of the Western Palearctic, Vol. 8. Oxford: Oxford University Press.

Dhondt, A.A. \& Eyckerman, R. 1979. Temperature and date of laying by tits Parus spp. Ibis 121: 329-331.

Donald, P.F., Green, R.E. \& Heath, M.F. 2001. Agricultural intensification and the collapse of Europe's farmland birds populations. Proc. R. Soc. Lond. B 268: 25-29.

Field, R.H. \& Anderson, G.Q.A. 2004. Habitat use by breeding Tree Sparrows Passer montanus. Ibis 146: 60-68.

Gustaffson, L. \& Nilsson, S.G. 1985. Clutch size and breeding success of Pied and Collared Flycatchers Ficedula spp. in nest-boxes of different sizes. Ibis 127: 380-385.

Haftorn, S. 1988. Incubating female passerines do not let the egg temperature fall below the physiological zero temperature during their absences from the nest. Ornis Scand. 19: 97110.

Isenmann, P., Dubray, D., Baouab, R. \& Thévenot, M. 1982. First results of clutch-size and breeding time of Blue Tit (Parus caeruleus) in Morocco. Vogelwarte 31: 461-463.
Karlsson, J. \& Nilsson, S.G. 1977. The influence of nest-box area on clutch size in some hole nesting passerines. Ibis 119: 207-211.

Kendeigh, S.C. 1969. Energy responses of birds to thermal environments. Wilson Bull. 81: 441-449.

King, D.I., De Graaf, R.M., Griffin, C.R. \& Maier, T.J. 1999. Do predation rates on artificial nests accurately reflect predation rates on natural bird nests? J. Field Ornithol. 70: 257-262.

King, J.R. \& Farner, D.S. 1961. Energy metabolism, thermoregulation, and body temperature. In Marshall, A.J. (ed.) Biology and Comparative Physiology of Birds, Vol. II: 215-288. New York: Academic Press.

Kluijver, H.N. 1952. Notes on body weight and time of breeding in the Great Tit Parus m. major L. Ardea 39: 123-141.

Lack, D. 1966. Population Studies of Birds. Oxford: Clarendon Press.

Major, R.E. \& Kendal, C.E. 1996. The contribution of artificial nest experiments to understanding avian reproductive success: a review of methods and conclusions. Ibis 138: 298-307.

McCleery, R.H., Clobert, J., Julliard, R. \& Perrins, C.M. 1996. Nest predation and delayed cost of reproduction in the great tit. J. Anim. Ecol. 65: 96-104.

Meijer, T., Nienaber, U., Langer, U. \& Trillmich, F. 1999. Temperature and timing of egg-laying in European Starlings. Condor 101: 124-132.

Mezquida, E.T. \& Marone, L. 2003. Are results of artificial nest experiments a valid indicator of success of natural nests? Wilson Bull. 115: 270-276.

Mitrus, C. 2003. A comparison of the breeding ecology of Collared Flycatchers nesting in boxes and natural cavities. J. Field Ornithol. 74: 293-299.

Moali, A., Akil, M. \& Isenmann, P. 1992. Modalités de la reproduction de deux populations de mésange bleue (Parus caeruleus ultramarines) en Algérie. Rev. Ecol. Terre Vie 47: 313-318.

Møller, A.P. 1989. Parasites, predators and nest boxes: facts and artefacts in nest box studies of birds? Oikos 56: 421423.

Nager, R.G. \& van Noordwijk, A.J. 1992. Energetic limitation in the egg-laying period of great tits. Proc. R. Soc. Lond. B 249: 259-263.

O'Connor, R.J. 1978. Nest-box insulation and the timing of laying in the Wytham Woods population of Great Tits Parus major. Ibis 120: 534-537.

Pendlebury, C.J., McLeod, M.G. \& Bryant, D.M. 2004. Variations in temperature increase the cost of living birds. J. Exp. Biol. 207: 2065-2070.

Perrins, C.M. 1970. The timing of birds' breeding seasons. Ibis 112: 242-255.

Perrins, C.M. 1996. Eggs, egg formation and the timing of breeding. Ibis 138: 2-15.

Perrins, C.M. \& McCleery, R.H. 1989. Laying dates and clutch size in the Great Tit. Wilson Bull. 101: 236-253.

Pulido, F.J. \& Díaz, M. 2000. Foraging behaviour of Blue Tits Parus caeruleus in a patchy environment under contrasting levels of natural food suppy. J. Avian Biol. 31: 81-86.

Purcell, K.L., Vermer, J. \& Oring, L.W. 1997. A comparison of the breeding ecology of birds nesting in boxes and tree cavities. Auk 114: 646-656.

Robinson, W.D., Styrsky, J.N. \& Brawn, J.D. 2005. Are artificial bird nests effective surrogates for estimating predation of real bird nests? A test with tropical birds. Auk 122: 843-852. 
Sánchez-Aguado, F.J. 1984. Fenología de la reproducción y tamaño de puesta en el Gorrión Molinero, Passer montanus L. Ardeola 31: 33-45.

Slagsvold, T. 1976. Annual and geographic variation in the time of breeding of the Great Tit Parus major and the Pied Flycatcher Ficedula hypoleuca in relation to environmental phenology and spring temperature. Ornis Scand. 7: 127145.

Stevenson, I.R. \& Bryant, D.M. 2000. Avian phenology - climate change and constraints on breeding. Nature 406: 366367.

Summers-Smith, J.D. 1995. The Tree Sparrow. Guisborough: J. Denis Summers-Smith.

Svensson, L. 1992. Identification Guide to European Passerines. Stockholm: Fingraf $A B$.

Thomas, W.D., Blondel, J. \& Perret, P. 2001. Physiological ecology of Mediterranean Blue Tits (Parus caeruleus). A test for inter-population differences in resting metabolic rate and thermal conductance as a response to hot climates. Zoology 104: 33-40.

Visser, M.E., van Noordwijk, A.J., Tinbergen, J.M. \& Lessells, C.M. 1998. Warmer springs lead to mis-timed reproduction in great tits (Parus major). Proc. $R$. Soc. Lond. B 265: 1867-1870.

Wilson, G.R., Brittingham, M.C. \& Goodrich, L.J. 1998. How well do artificial nests estimate success of real nests? Condor 100: 357-364.

Yom-Tov, Y. \& Hilborn, R. 1981. Energetic constraints on clutch size and time of breeding in temperature zone birds. Oecologia 48: $234-243$.

Yom-Tov, Y. \& Wright, J. 1993. Effect of heating nest-boxes on egg-laying in the Blue Tit (Parus caeruleus). Auk 110: 95-99.

Received 3 August 2007;

revision accepted 19 December 2007. 